\title{
Utility of the Abdominometer: A Novel Contribution to Cardiovascular Anthropometry
}

\author{
Basil N. Okeahialam ${ }^{*}$, Udochukwu M. Diala², Jones Uwakwe', Ijeoma Ejeh ${ }^{3}$, Ugochi Ozoilo4 \\ ${ }^{1}$ Department of Medicine, Jos University Teaching Hospital, Jos, Nigeria \\ ${ }^{2}$ Department of Paediatrics, Jos University Teaching Hospital, Jos, Nigeria \\ ${ }^{3}$ Department of Histopathology, Jos University Teaching Hospital, Jos, Nigeria \\ ${ }^{4}$ Department of Community Medicine, Jos University Teaching Hospital, Jos, Nigeria \\ Email: "basokeam@yahoo.com
}

Received 13 August 2015; accepted 9 October 2015; published 13 October 2015

Copyright $@ 2015$ by authors and Scientific Research Publishing Inc.

This work is licensed under the Creative Commons Attribution International License (CC BY).

http://creativecommons.org/licenses/by/4.0/

\begin{abstract}
Obesity is a CVD risk factor that can be modulated for massive reduction in morbi-mortality. Traditional indices measuring it have been inconsistent and the most commonly used; BMI has proved inappropriate for Africans, not attending specifically to body fat and its distribution. With the consensus that intra-abdominal fat is the most critical for cardio-metabolic diseases, various attempts were made to measure it for risk estimation. These however require costly equipments not easily amenable for population studies. The abdominometer conceptualized by BNO has shown promise in isolated cases. This pilot study was undertaken in this restricted population to compare its utility with existing anthropometric measures of cardiovascular disease.
\end{abstract}

\section{Keywords}

Obesity, Abdominometer, Anthropometry, Africa

\section{Introduction}

Obesity is a disease [1] which is a harbinger of death given its contribution to morbidity and premature death [2]. Its clinical and metabolic consequences result in heart failure, stroke, kidney failure and myocardial infarction; leading to death and disability. It is also related to reduced mobility, peripheral artery disease, sexual dysfunction, some cancers, cosmetic encumbrances and degenerative diseases of the joints. These impair the quality of

\footnotetext{
"Corresponding author.
}

How to cite this paper: Okeahialam, B.N., Diala, U.M., Uwakwe, J., Ejeh, I. and Ozoilo, U. (2015) Utility of the Abdominometer: A Novel Contribution to Cardiovascular Anthropometry. Food and Nutrition Sciences, 6, 1202-1207. 
life by their physical and psychological impacts. It has been on the rise all over the world. More than one third United States of America adults are obese [3]. It has also risen in some sub-Saharan native groups [4]. The rapid rise in obesity rates and the costs for treating it and its cardio-metabolic consequences make obesity research be crucial [5].

Its previous indices of measurement such as Body Mass Index (BMI) and Waist Circumference (WC) are not equally applicable to all ethnic groups [2] and current cut-off values may not be appropriate for Africans [6]. BMI has for long served as a useful proxy determinant of obesity but its deficiency is in its inability to distinguish contribution of body frame size, muscle mass and body fat to overall weight [7]. In fact, it misses subjects with increased cardio-metabolic risk factors related to increased adiposity [8]. WC as a measure of abdominal obesity is more useful in assessing cardio-metabolic risks, and is a stronger measure in some ethnic groups [9]. Since body fat especially intra-abdominal with its attendant insulin resistance is central to all cardio-metabolic risks, there has been a shift to using anthropometric measures to target it for routine assessment of metabolic and cardiovascular disease (CVD) risk [10]. With the finding that percentage body fat tracks blood pressure better than BMI in an African population [11], and the position that abdominal height is a better predictor of CVD than any other anthropometric measurement [12], one of us (BNO) thought of how to measure it in our population using simple and adaptable equipment. This gave rise to the "abdominometer".

Measurement of abdominal height (AH) that some workers refer to as sagital abdominal diameter has shown better correlation with CVD risk factors than WC and BMI [13], and stronger measure of abdominal fat than WC [14]. This is because WC does not always mirror visceral obesity as it may have a bearing on abdominal sub-cutaneous fat [15]. The beauty of this implement called the "abdominometer" is its portability. Its use is simple. Once the anatomical landmarks are recognized, any one without much education can use it. Unlike the Brazilian apparatus measuring the sagital abdominal diameter [16], it is not fixed to the couch. That way, it could be used in the field and moved about easily. We therefore used this implement in the course of this community service to see its utility in cardiovascular screening.

Ezinihitte is one of the 5 clans that make up Mbaise in present Imo State of Nigeria. Its people are Ibos, and almost complete Christians of various denominations. In 2013, natives of Ezinihitte resident in Jos and belonging to Ezinihitte Development Association Jos Branch were screened for CVDs. This followed a series of death of members related to CVDs. The team was led by BNO who had conceptualized the "abdominometer", used to measure abdominal height and used as part of the evaluation. Following the invitation by members in a general meeting early in 2013 to BNO to screen them for hypertension related diseases following a string of hypertension related deaths in members, a team made up of all Ezinihitte born doctors in Jos University Teaching Hospital was raised. It was agreed that the meeting of August 2013 would be dedicated to this. All the 56 members ( $51 \mathrm{M}, 5 \mathrm{~F}$ ) who turned up for the meeting were invited for screening.

\section{Methodology}

All the equipments were checked for accuracy and members of the team tried out their hands on abdominal height measurement with the "abdominometer" to ensure uniformity with its use. The session began with instruction to members on the procedure to be adopted and request of informed consent to participate. All the 56 members of the association who were in attendance at that monthly meeting of August 2013 were invited to participate. Inclusion criteria were being a member of Ezinihitte Development Association in Jos and being present at the August 2013 meeting which had earlier been agreed to be set aside for the cardiovascular disease screening. Only those who voluntarily declined participation were excluded. The protocol had earlier been approved by the Research Ethics Committee of Jos University Teaching Hospital. They then came orderly through different desks manned by one member of the team as follows.

Desk 1: Name, age, gender, history of smoking and Diabetes Mellitus were documented.

Desk 2: Blood pressure measurement in standard sphygmomanometric fashion (ACCOSON BRAND with appropriate cuff).

Desk 3: Abdominal height measurement with the "abdominometer". It is made of wood in L shape (Figure 1). The short arm rests in the small of the back at the level of the iliac crest which corresponds to the space between the $4^{\text {th }}$ and $5^{\text {th }}$ lumbar vertebrae. The longer arm has a sliding and swinging mechanism that moves anteriorly to come to rest on the anterior abdominal wall at the level of the umbilicus or the anterior most point of the abdomen at that level; for those with pendulous abdomen. This level is then read off on the laminated graduated scale in centimeters (Figure 2). 


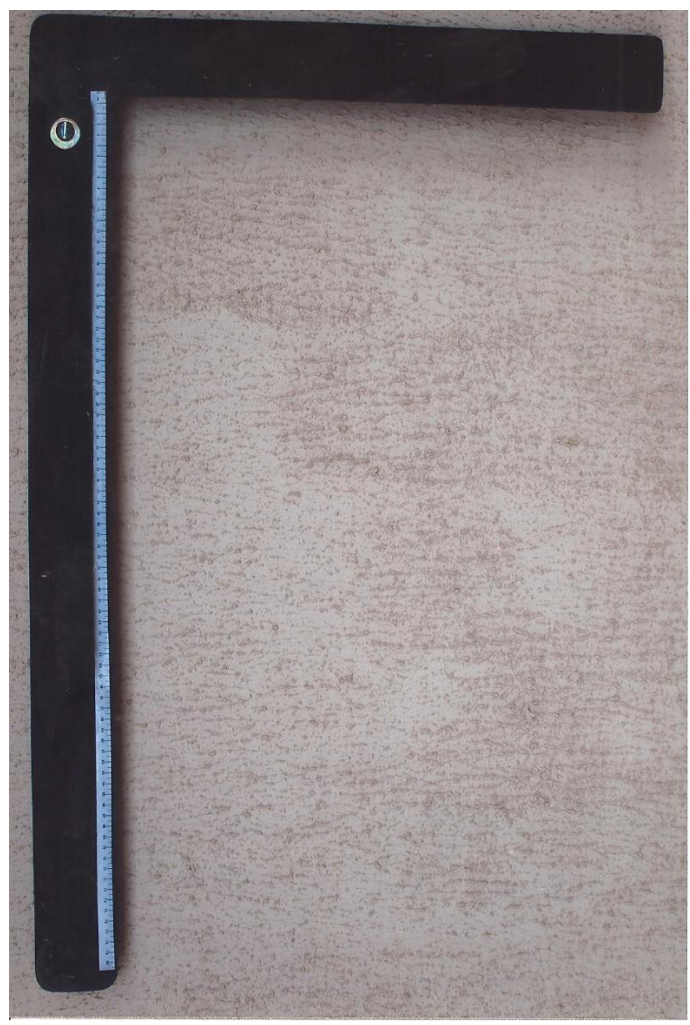

Figure 1. The abdominometer in closed position. The short arm rests in the small of the back and the long arm with the measuring scale and sliding and swinging mechanism completes the motion for $\mathrm{AH}$ measurement.

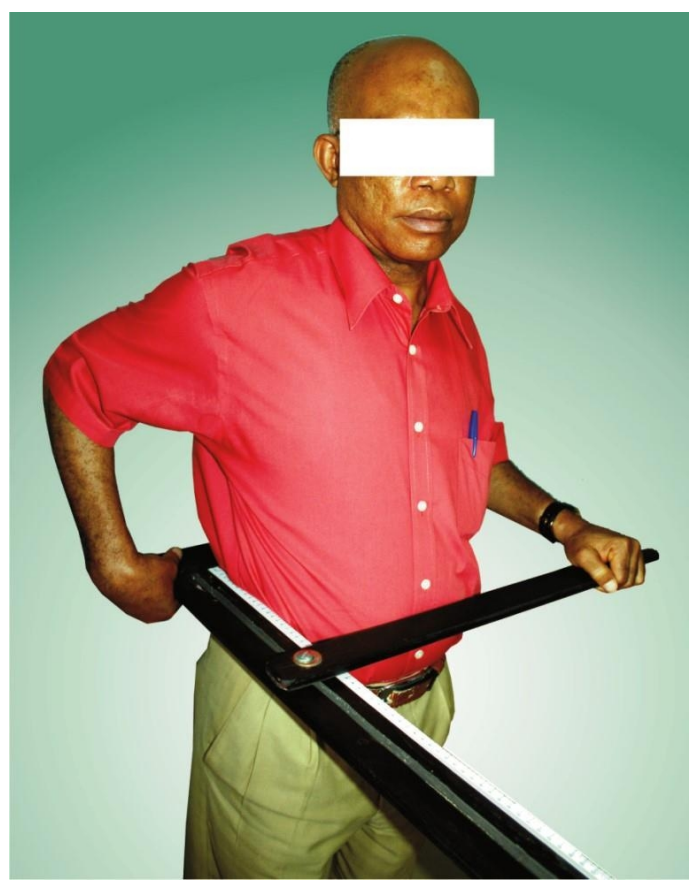

Figure 2. BNO showing on himself the position of the abdominometer on the anterior abdominal wall at the level of the umbilicus for reading off of $\mathrm{AH}$. 
Desk 4: Height measurement using a stadiometer in standard fashion; read off in metres.

Desk 5: Weight and percentage body fat (\%BF) were measured using an electronic scale (body fat bath scale -Nature's Gift for Life, 13303 Summer Terrace Drive, Sugar Land, Texas 77497 USA). BMI was derived as quotient of weight in kilograms and the square of height in meters.

Data were analysed using SPSS Version 16 statistical software. Data are presented as mean (SD) and subjected to Pearson correlation as appropriate. Significance was set at $\mathrm{p} \leq 0.05$

\section{Results}

Fifty four people (49 $\mathrm{M}$ and $5 \mathrm{~F}$ ) had complete data for BMI, AH and BP while 29 had data for \%BF. Mean (SD) values were 26.18 (4.14), 24.65 (4.06), 135.79 (22.91), 84.28 (15.81) and 28.09 (8.11) for BMI, AH, SBP, DBP and \%BF respectively. They were largely artisans and traders with a few being employed in the formal sector of the economy. Their ages ranged from 30 to 75 years, 7 were smokers, 1 had diabetes mellitus and 20 were hypertensive. Among the 29 with all data (27 M, 2 F), AH correlated significantly with BMI (Pearson correlation coefficient, $\mathrm{R}=0.803)$ and $\% \mathrm{BF}(\mathrm{R}=0.797)$ at $\mathrm{p}=0.01$. Whereas $\mathrm{BMI}$ did not significantly correlate with both SBP and DBP, AH correlated with SBP $(\mathrm{R}=0.307$; $\mathrm{p}=0.05)$ while \%BF correlated with both SBP and $\mathrm{DBP}(\mathrm{R}=0.402$ and 0.421 respectively; $\mathrm{p}=0.05)$.

\section{Discussion}

Excess fat defines overweight/obesity status; and when in ectopic foci like the visceral compartment is dysfunctional [17]. Obesity leads to several co-morbidities, the severity of which is proportional to excess body fat [18]. The current definitions of obesity using BMI have shown not to apply well for Africans [6]. While widely used to monitor prevalence of obesity, it does not consider distribution [19] which varies by ethnic groups. Because different anthropometric measures factor in body fat differently, their use in screening for CVD has yielded inconsistent results [20].

As different populations have differences in the predictive values of \%BF at given BMI, the need for population specific anthropometry became compelling [21].

Our study is preliminary; and used the "abdominometer”, a new apparatus to measure AH as a cardiovascular anthropometric index. That it correlated significantly with BMI and \%BF, long standing cardiovascular anthropometric measures, shows that AH determined by this apparatus is effective. When each of the cardiovascular anthropometric measures in this study was correlated with SBP and DBP, BMI did not attain significance. This would confirm the observation that BMI misses subjects whose cardio-metabolic risk is related to increased adiposity [8] and is inappropriate for Africans [22]. Sagital abdominal diameter was shown to correlate better with CVD risk factors than BMI [13]. Given its greater contribution to prediction of BP than other measures of central obesity, AH was recommended for use to assess a component of visceral fat that other anthropometric measures miss [23]. \%BF appeared to be the best measure but it requires electronic equipment which is expensive and needing battery replacements. Our “abdominometer” readings tracked SBP at the same level as \%BF, but lagged behind for DBP. This may not be a significant disability as SBP has been acclaimed the predominant risk factor in middle aged and older adults on both conventional and blood pressure measurement [24].

This study is limited by a small sample size and restricted ethnic representation. It however holds a promise of being a simple, mobile and efficient cardiovascular screening measure that targets abdominal visceral fat; the major contributor to cardio-metabolic complications [15].

\section{Conclusion}

In conclusion the abdominometer-measured $\mathrm{AH}$ is better than traditional cardiovascular anthropometric measures in this African cohort, and should be used more widely to authenticate its benefit.

\section{Acknowledgements}

Mr. Ethelbert Agwulonu, a private wood worker in Jos gave form to this concept. Mr. Jeremiah Shidda of the Medical Illustration and Technology Unit of the Faculty of Medical Sciences, University designed an attachment of the measuring scale onto the implement. 


\section{References}

[1] Mechnaick, J.I., Garber, A.J., Handelsman, Y. and Gawey, W.T. (2012) American Association of Clinical Endocrinologists Position Statement on Obesity and Obesity Medicine. Endocrine Practice, 18, 642-648. http://dx.doi.org/10.4158/EP12160.PS

[2] Wimalawansa, S.J. (2013) Thermogenesis-Based Interventions for Obesity and Type 2 Diabetes Mellitus. Expert Review of Endocrinology \& Metabolism, 8, 275-280. http://dx.doi.org/10.1586/eem.13.13

[3] Ogden, C.L., Carole, M.D., Kit, B.K. and Flegal, K.M. (2012) Prevalence of Obesity in the United States 2009-2010. NCHS Data Brief, 82, 1-8.

[4] Ekezie, J., Anyanwu, E.G., Danborno, B. and Ugochukwu, A. (2011) Impact of Urbanization on Obesity, Anthropometric Profile and Blood Pressure in the Igbos of Nigeria. North American Journal of Medicine \& Science, 3, 242-246. http://dx.doi.org/10.4297/najms.2011.3242

[5] Karatsoreos, I.N. (2014) The Relationship between Circadian Disruption and the Development of Metabolic Syndrome and Type 2 Diabetes. ChronoPhysiology and Therapy, 4, 137-145. http://dx.doi.org/10.2147/CPT.S44799

[6] Murphy, G.A.V., Asiki, G., Nsubuga, R.N., Young, E.H., Seeley, J., Sandhu, M.S. and Kamali, A. (2014) The Use of Anthropometric Measures for Cardiometabolic Risk Identification in a Rural African Population. Diabetes Care, 37, e64-e65. http://dx.doi.org/10.2147/CPT.S44799

[7] Ashwell, M. (2011) Shape. The Waist-To-Height Ratio Is a Good Sample Screening Tool for Cardiometabolic Risk. Nutrition Today, 46, 85-89. http://dx.doi.org/10.1097/NT.0b013e3182118779

[8] Gomez-Ambrosi, J., Silva, C., Galofre, J.C., Escalada, J., Santos, S., Millan, D., Vila, N., Ibanez, P., Gil, M.J., Valenti, V., Rotellar, F., Ramirez, B., Salvador, J. and Fruhbeck, G. (2012) Body Mass Index Classification Misses Subjects with Increased Cardiometabolic Risk Factors Related to Elevated Adiposity. International Journal of Obesity, 36, 286294. http://dx.doi.org/10.1038/ijo.2011.100

[9] Dudeja, V., Misra, A., Pandey, R.M., Devina, G., Kumar, G. and Vikram, N.K. (2001) BMI Does Not Accurately Predict Overweight in Asian Indians in Northern India. British Journal of Nutrition, 86, 105-112. http://dx.doi.org/10.1079/BJN2001382

[10] Wimalawansa, S.J. (2013) Visceral Adiposity and Cardiometabolic Risk: Epidemic of Abdominal Obesity in North America. Research and Reports in Endocrine Disorders, 3, 1-14. http://dx.doi.org/10.2147/rred.s32041

[11] Okeahialam, B.N., Ebirim, C.I. and Onwubere, B.J.C. (2012) Comparative Assessment of Percentage Body Fat versus Body Mass Index as Anthropometric Measures of Blood Pressure. Circulation, 125, e877-e878.

[12] Iribarren, C., Darbinian, J.A., Lo, J.C., Fireman, B.H. and Go, A.S. (2006) Value of the Sagittal Abdominal Diameter in Coronary Heart Disease Risk Assessment: Cohort Study in a Large, Multi-Ethnic Population. American Journal of Epidemiology, 164, 1150-1159. http://dx.doi.org/10.1093/aje/kwj341

[13] deSouza, N.C. and de Oliveira, E.P. (2013) Sagittal Abdominal Diameter Shows Better Correlation with Cardiovascular Risk Factors than Waist Circumference and BMI. Journal of Diabetes and Metabolic Disorders, 12, 41. http://dx.doi.org/10.1186/2251-6581-12-41

[14] Pimentel, G.D., Portero-McLellan, K.C., Maesta, N., Corrente, J.E. and Burini, R.C. (2010) Accuracy of Sagittal Abdominal Diameter as a Predictor of Abdominal Fat among Brazilian Adults: A Comparison with Waist Circumference. Nutrition Hospitalaria, 25, 656-661.

[15] Whaley-Connell, A. and Sowers, J.R. (2011) Indices of Obesity and Cardiometabolic Risk. Hypertension, 58, $991-993$. http://dx.doi.org/10.1161/HYPERTENSIONAHA.111.180406

[16] Sampaio, L.R., Simoes, E.J., Assis, A.M. and Ramos, L.R. (2007) Validity and Reliability of Sagittal Abdominal Diameter as a Predictor of Visceral Abdominal Fat. Arquivos Brasileiros de Endocrinologia \& Metabologia, 51, 980-986. http://dx.doi.org/10.1590/S0004-27302007000600013

[17] Gupta, A.K., Johnson, W.D., Johannsen, J.D. and Ravussin, E. (2013) Cardiovascular Risk Escalation with Caloric Excess: A Prospective Demonstration of the Mechanics in Healthy Adults. Cardiovascular Diabetology, 12, 23. www.medscape.com http://dx.doi.org/10.1186/1475-2840-12-23

[18] Silva-Hamu, T.C.D., Formiga, C.K.M.R., Gervasio, F.M., Ribeiro, D.M., Christofoletti, G. and Barros, J.F. (2013) The Impact of Obesity in the Kinetic Parameters of Gait in Young Women. International Journal of General Medicine, 6, 507-513. http://dx.doi.org/10.2147/IJGM.S44768

[19] Shields, M., Tremblay, M.S., Gorber, S.C. and Janssen, I. (2012) Abdominal Obesity and Cardiovascular Disease Risk Factors within Body Mass Index Categories. Statistics Canada Catalogue No. 82-003-XPE. Health Reports, 23, 1-9.

[20] Czernichow, S., Kengne, A.P., Stamatakis, E., Hamer, M. and Batty, G.D. (2011) Body Mass Index, Waist Circumference and Waist-Hip Ratio: Which Is the Better Discriminator of Cardiovascular Disease Mortality Risk? Evidence 
from an Individual Participant Meta-Analysis of 82,864 Participants from Nine Cohort Studies. Obesity Reviews, 12, 680-687. http://dx.doi.org/10.1111/j.1467-789x.2011.00879.x

[21] Mendis, S. and Mohan, V. (2008) Non-Laboratory-Based Prediction of Cardiovascular Risk. Lancet, 371, 878-879. http://dx.doi.org/10.1016/S0140-6736(08)60392-X

[22] Motala, A.A., Esterhuizen, T., Pirie, F.J. and Omar, M.A. (2011) The Prevalence of Metabolic Syndrome and Determination of the Optimal Waist Circumference Cutoff Points in a Rural South African Community. Diabetes Care, 34, 1032-1037. http://dx.doi.org/10.2337/dc10-1921

[23] Gustat, J., Elkasabany, A., Srinivasan, S. and Berenson, G.S. (2000) Relation of Abdominal Height to Cardiovascular Risk Factors in Young Adults. The Bogalusa Heart Study. American Journal of Epidemiology, 151, 885-891. http://dx.doi.org/10.1093/oxfordjournals.aje.a010292

[24] Boggia, J., Thijs, L., Li, Y., Hansen, T.W., Kikuya, M., Bjorklund-Bodegard, K., et al., on Behalf of the International Database on Ambulatory Blood Pressure in Relation to Cardiovascular Outcomes (IDACO) Investigators (2013) Risk Stratification by 24-Hour Ambulatory Blood Pressure and Estimated Glomerular Filtration Rate in 5322 Subjects from 11 Populations. Hypertension, 61, 18-26. http://dx.doi.org/10.1161/HYPERTENSIONAHA.112.197376 